\title{
Desempenho do feijão-caupi a densidades de plantas na região Norte da Bahia $^{1}$
}

\author{
Daise Feitoza da Rocha ${ }^{2}$, Gertrudes Macário de Oliveira², Luciano Roniê Calado de Almeida², Allan \\ Victor Araújo Pereira², Gabriela Vieira de Sá Santos ${ }^{2}$
}

Resumo: A densidade de plantas é um dos fatores de produção que contribuem para a ótima produtividade e qualidade de grãos. Neste sentido, com o estudo objetivou avaliar a resposta de feijão-caupi a densidades populacionais na região Norte da Bahia. O experimento foi conduzido no período de abril a junho de 2018, na área experimental do Departamento de Tecnologia e Ciências Sociais da UNEB, Juazeiro, BA. Utilizou-se o delineamento casualizado em blocos no esquema de parcelas subdivididas, sendo as parcelas constituídas por duas cultivares de feijão-caupi (BRS Acauã e BRS Tapaihum) e as subparcelas, cinco espaçamentos, resultando em cinco densidades de plantio: 66.667; 80.000; 100.000; 133.333 e 200.000 plantas ha ${ }^{-1}$, dez repetições. As variáveis analisadas foram: altura da planta, número de vagens por planta, peso de 10 vagens, comprimento de vagem, peso de 100 grãos e rendimento de grãos. Não foi observado efeito significativo de interação entre cultivar e densidades de plantas de feijão-caupi para nenhuma das variáveis analisadas. $\mathrm{O}$ aumento da densidade de 66.667 para 200.000 mil plantas ha ${ }^{-1}$ resultou em acréscimo de $23 \%$ na altura média das plantas, redução de $64 \%$ no número de vagens por planta e aumento de aproximadamente $117 \%$ no rendimento de grãos. Recomenda-se a densidade de 200.000 plantas ha $^{-1}$ para incrementos na produtividade de grãos de feijão-caupi na região Norte da Bahia.

Palavras-chave: Vigna unguiculata; espaçamentos entre plantas; rendimento de grãos.

\section{Cowpea performance at plants densities in the North region of Bahia}

\begin{abstract}
The plant density is one of the factors of production which contribute to optimum yield and grain quality, the objective of this study was to evaluate the response of cowpea to different plant densities in the north region of Bahia. The experiment was conducted from april to june at 2018, in the experimental area of the Department of Technology and Social Sciences of UNEB, Juazeiro, BA. A randomized block design was used in the subdivided plots scheme, the plots consisted of cowpea (BRS Acauã and BRS Tapaihum) and subplot, five spacing, resulting in five different planting densities: 66.667; 80.000; 100.000; 133.333 and 200.000 plants ha ${ }^{-1}$, ten replicates. The variables analyzed were: plant height, number of pods per plant, weight of 10 pods, pod length, weight of 100 grains and yield of grains. There was no significant effect of the interaction between grow crops and plants densities of cowpea in any of the analyzed variables. The density increase from 66.667 to 200.000 plants $^{-1} \mathrm{a}^{-1}$ resulted in an increase of $23 \%$ in the average height of the plants, a $64 \%$ reduction in the number of pods per plant and an increase of approximately $117 \%$ in the yield of grains. Density of 200,000 plants $\mathrm{ha}^{-1}$ is recommended for increases in cowpea grain yield in north of Bahia.
\end{abstract}

Keywords: Vigna unguiculata; plant spacings; grain yield.

\footnotetext{
${ }^{1}$ Submetido em 23/04/2019 e aprovado em 15/10/2019;

${ }^{2}$ Departamento de Tecnologia e Ciências Sociais, Universidade do Estado da Bahia, Juazeiro, Bahia, Brasil; E-mail: daiserocha11@gmail.com - ORCID: 0000-0001-9998-8191; gmacariodeoliveira@yahoo.com.br - ORCID: 0000-0002-7587-5800; caladoroni@gmail.com - ORCID: 0000-0002-1993-1900; allan.v1997@gmail.com $\quad$ - ORCID: 0000-0001-8707-1140; gabrielavieira.sa@gmail.com - ORCID: 0000-0002-1341-5200.
} 


\section{Introdução}

O feijão-caupi [Vigna unguiculata (L.) Walp.] é uma excelente fonte de nutrientes composto por proteínas, carboidratos, vitaminas e minerais. Caracteriza-se, como um alimento essencial para as populações de baixa renda do Norte e Nordeste brasileiro (Rocha et al., 2017). Seu cultivo possui grande importância socioeconômica para essas regiões, sobretudo para habitantes da zona rural, uma vez que é encarregado por fixar mão-de-obra no campo, gerar emprego e renda (Freire Filho, 2011).

A produção mundial de feijão-caupi em 2017 foi de aproximadamente 7,4 milhões de toneladas, produzido em 12,6 milhões de hectares, com uma produtividade média de 589,0 $\mathrm{kg} \mathrm{ha}{ }^{-1}$ (FAO, 2018). Segundo estimativas da Embrapa Arroz e Feijão (2018), a produção do feijão-caupi no Brasil em 2017 foi cerca de 647.143 toneladas colhidas em 1,39 milhões de hectares, com uma produtividade média de 466 $\mathrm{kg} \mathrm{ha}^{-1}$.

A produtividade do feijão-caupi pode ser influenciada pelas condições de solo, clima, manejo de irrigação, tratos culturais, adubação e efeito residual do adubo (Bezerra et al., 2014; Cardoso e Melo, 2017). Silva et al. (2014) observaram incremento de $25 \%$ da produtividade de vagens e $50 \%$ da produtividade de grãos, utilizando $100 \%$ acima do recomendado das doses de nitrogênio, fósforo e potássio. Locatelli et al. (2013) verificaram que a produtividade de vagens foi influenciada pelas lâminas de irrigação, atingindo a máxima eficiência técnica para produtividade de $8395,5 \mathrm{~kg} \mathrm{ha}^{-1}$ com a lâmina $87 \%$ da evapotranspiração de referência.

Entretanto, para se alcançar o máximo potencial produtivo do feijão-caupi, deve-se considerar também, o número de plantas por área, a qual influência diretamente as características morfológicas, fisiológicas e de rendimento de grãos (Bezerra et al., 2014). Segundo Silva Júnior et al. (2012), um bom arranjo de plantas pode favorecer o surgimento de plantas mais produtivas, aumentando o estande produtivo final e, consequentemente, o rendimento de grãos.

De acordo com Oliveira (2013) a densidade e o arranjo de plantas irão determinar o grau de competição e o estádio em que ela será mais intensa entre as plantas. E, segundo Bezerra et al. (2008) a competição em intensidade elevada, nos estádios iniciais do desenvolvimento da cultura, pode favorecer o surgimento de plantas improdutivas, causar a diminuição do estande produtivo final e, consequentemente, o rendimento de grãos.

Alterações na densidade de plantas proporcionam diferenças significativas na morfologia da planta, com reduções do diâmetro do caule e do número de ramos laterais, bem como nos componentes de produção, com reduções no número de vagens por planta, na produção de grãos por planta e rendimento de grãos (Bezerra et al., 2012). O espaçamento entre fileiras e a densidade populacional determinam o nível de competição entre as plantas; esta combinação tem influência direta no aproveitamento da luz, água e nutrientes (Camara et al. 2018).

O porte, a arquitetura e o sistema de produção são apontados por Bezerra et al. (2012), como fatores que influenciam na determinação do arranjo de plantas mais adequado para que os fatores ambientais sejam eficientemente aproveitados, e a cultivar expresse seu potencial máximo de produção. Essa influência leva a busca pela determinação de uma densidade ótima para cada cultivar (Sousa, 2017).

Outro ponto importante, destacado por Cardoso e Melo (2017), é que a quantidade de água do solo extraída pelas raízes do feijão-caupi é diretamente proporcional às densidades de plantas; quanto maior a densidade de plantas, mais água as raízes extraem do solo. Portanto, o aumento na densidade de plantas em regiões com limitações hídricas, pode se tornar um entrave para que a cultura expresse seu máximo potencial produtivo.

Considerando que a densidade de plantas é um dos fatores de produção que contribuem para uma ótima produtividade e maior qualidade de grãos, objetivou-se com este estudo, avaliar a resposta do feijão-caupi a densidades populacionais na região Norte da Bahia.

\section{Material e Métodos}

O experimento foi conduzido na área experimental localizada em frente à estação meteorológica do Departamento de Tecnologia e Ciências Sociais - DTCS, da Universidade do 
Estado da Bahia - UNEB, município de Juazeiro

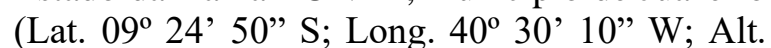
$368 \mathrm{~m}$ ), no período de abril a junho de 2018. O clima da região, segundo a classificação de Köppen é do tipo Bswh', semiárido. O solo da área experimental foi classificado como Neossolo Flúvico.

A área experimental foi preparada com aração e gradagem, posteriormente, foi instalado o sistema de irrigação por gotejamento com emissores espaçados a $0,20 \mathrm{~m}$, vazão de $1,75 \mathrm{~L}$ $\mathrm{h}^{-1} \mathrm{e}$ pressão de serviço de $1,0 \mathrm{kgf} \mathrm{cm}^{-2}$. Utilizouse o delineamento casualizado em blocos no esquema de parcelas subdivididas, sendo as parcelas constituídas por duas cultivares de feijão-caupi (BRS Acauã e BRS Tapaihum) e as subparcelas os cinco espaçamentos na linha $(0,10 ; 0,15 ; 0,20 ; 0,25$ e $0,30 \mathrm{~m})$, dez repetições. Cada unidade experimental foi formada por três linhas de $18 \mathrm{~m}$ de comprimento. Foi classificada como parcela útil a linha central, desconsiderando as plantas da bordadura.

O genótipo BRS Tapaihum é resultante do cruzamento entre a cultivar Epace 11 e o acesso 293588. É uma cultivar de feijão-caupi de tegumento preto, porte ereto e crescimento semi determinado, para áreas irrigadas e de sequeiro da Bahia, Pernambuco e Piauí. A BRS Acauã é a primeira cultivar do grupo Canapu, desenvolvida pela Embrapa Semiárido, originada do cruzamento entre a BR 10 Gurgueia x 'Canapu', oriundo de Casa Nova, BA; é caracterizada pelo crescimento indeterminado e porte semiramador, possui ampla adaptação aos sertões da Bahia, Pernambuco e Piauí, com melhor comportamento em condições irrigadas (Santos, 2011). Ambos os genótipos foram adquiridos na EMBRAPA Semiárido.

A semeadura do feijão foi feito no dia 07 de abril de 2018 colocando-se em média, três sementes por cova, a uma profundidade média de 2 a $3 \mathrm{~cm}$; sendo adotado o espaçamento fixo de 0,50 m entre linhas, combinado com os cinco espaçamentos entre plantas, resultando em cinco densidades: 200.000; 133.333; 100.000; $80.000 \mathrm{e}$ 66.667 plantas $\mathrm{ha}^{-1}$. O desbaste de plantas foi feito 20 dias após a semeadura, no estádio de desenvolvimento V4 (terceira folha trifoliolada, com folíolos expandidos), mantendo uma planta por cova.
A irrigação foi feita com base na evapotranspiração de referência (ETo), estimada diariamente por meio do método do tanque classe A, instalado na área da estação meteorológica, localizada a $12 \mathrm{~m}$ da área experimental. A evapotranspiração da cultura (ETc) foi obtida pela equação: $\mathrm{ETc}=\mathrm{Kc}$ ETo, onde $\mathrm{Kc}$ é o coeficiente de cultura. Foram utilizados valores de $\mathrm{Kc}$ para os diferentes estádios de desenvolvimento do feijão-caupi propostos na literatura.

Aos 63 dias após o plantio (DAP) do feijãocaupi, dentre o estande da parcela útil, foram selecionadas aleatoriamente três plantas para a avaliação das variáveis: altura da planta $(\mathrm{cm})$ e número de vagem por planta. Foram avaliados também os componentes de produção para feijão seco: peso de dez vagens (g), comprimento de dez vagens $(\mathrm{cm})$, peso de cem grãos $(\mathrm{g})$ e rendimento de grãos $\left(\mathrm{kg} \mathrm{ha}^{-1}\right)$. Os dados foram submetidos à análise de variância com aplicação do teste F, utilizando o software SISVAR, versão 5.6. Para os fatores qualitativos utilizouse teste de comparação de médias (Tukey a 5\% de probabilidade) e para os fatores quantitativos, regressão polinomial.

\section{Resultado e Discussão}

A interação entre cultivar e densidade de plantas de feijão-cupi foi não significativa para as variáveis estudadas. Considerando os fatores isolados, constatou-se efeito significativo apenas para o fator densidade nas variáveis: altura de planta (AP), número de vagens por planta (NVP) e rendimento de grãos (Tabela 1).

Observou-se diminuição da altura de plantas (AP) com o aumento do espaçamento (menor densidade de plantas) das cultivares de feijãocaupi estudadas (Figura 1). Constatou-se um acréscimo de $23 \%$ na altura média das plantas correspondentes a densidade de 200.000 plantas $\mathrm{ha}^{-1}$ (espaçamento $=10 \mathrm{~cm}$ ), comparada à densidade de 66.667 plantas ha $^{-1}$ (espaçamento $=$ $30 \mathrm{~cm}$ ), cujas médias foram respectivamente, 37,1 e $30,2 \mathrm{~cm}$. Provavelmente, o maior adensamento proporcionou sobreposição de folhas das plantas e consequentemente, sombreamento, concorrendo para a planta ir à procura de luz, favorecendo a maior altura de planta. A sobreposição de folhas como fator que interfere na competição por luz entre plantas, foi reportado por Guimarães et al. (2017). Oliveira 
(2014) relata que o adensamento da cultura pode alterar o agroecossistema, modificando a disponibilidade de fatores como luz, $\mathrm{CO}_{2}$ e temperatura, afetando diretamente características morfológicas da planta. Brito (2014) destaca que o desenvolvimento do dossel da cultura está intimamente relacionado com a interceptação de luz e consequentemente, com a atividade fotossintética realizada; e alterações nos espaçamentos, seja entre linhas ou entre plantas, tendem a influenciar no aproveitamento da energia luminosa pelas plantas.

Tabela 1 Resumo das análises de variância (Valores de F) para as variáveis: altura de planta (AP), número de vagem por planta (NVP), comprimento de vagens (CV), peso de 10 vagens (P10V), peso de 100 grãos (P100G) e rendimento de grãos (REND) de cultivares de feijão-caupi (C), em função da densidade de plantas (D)

\begin{tabular}{llllllll}
\hline FV & GL & AP & NVP & CV & P10V & P100G & REND \\
\hline Blocos & 2 & $0,752^{\text {ns }}$ & $0,429^{\text {ns }}$ & $2,795^{\text {ns }}$ & $1,396^{\text {ns }}$ & $1,602^{\text {ns }}$ & $11,220^{\text {ns }}$ \\
Cultivar (C) & 1 & $0,598^{\text {ns }}$ & $6,036^{\text {ns }}$ & $1,425^{\text {ns }}$ & $6,299^{\text {ns }}$ & $0,531^{\text {ns }}$ & $0,619^{\text {ns }}$ \\
Erro 1 & 2 & - & - & - & - & - & - \\
Densidade(D) & 4 & $5,672^{*}$ & $4,678^{*}$ & $0,458^{\text {ns }}$ & $2,161^{\text {ns }}$ & $1,402^{\text {ns }}$ & $15,825^{*}$ \\
C x D & 4 & $1,496^{\text {ns }}$ & $0,678^{\text {ns }}$ & $2,396^{\text {ns }}$ & $2,096^{\text {ns }}$ & $0,131^{\text {ns }}$ & $0,266^{\text {ns }}$ \\
Erro 2 & 16 & - & - & - & - & - & - \\
\hline CV 1 $(\%)$ & & 9,75 & 16,37 & 5,60 & 8,18 & 18,37 & 6,12 \\
CV 2 $\%)$ & & 9,10 & 24,22 & 4,31 & 9,72 & 9,37 & 19,01 \\
\hline
\end{tabular}

${ }^{\mathrm{FV}}$ Fonte de variação; ${ }^{\mathrm{ns}}$ não significativo; * significativo a $5 \%$ de probabilidade pelo teste $\mathrm{F}$.

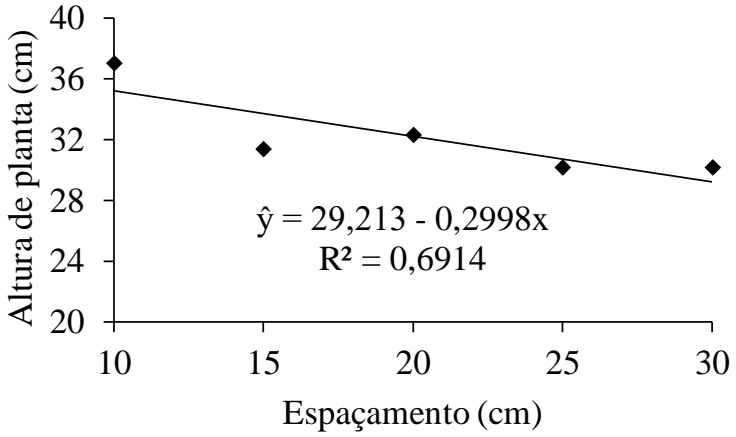

Figura 1 Altura média de planta de feijão-caupi em função de diferentes espaçamentos.

Quanto ao número de vagens por planta (NVP), aumentou com a diminuição da densidade populacional das cultivares de feijãocaupi (Figura 2). O aumento da densidade populacional de 66.667 para 200.000 plantas ha $^{-1}$ reduziu o número de vagens por planta em $64 \%$, passando de 7,0 para 4,5 , respectivamente. Constata-se, portanto, que o menor adensamento contribuiu para maior penetração da luz solar no interior da planta, aumentando a produção de vagens, corroborando com Taiz e Zeiger (2013) ao afirmar que, mais folhas expostas a luz, tende a favorecer a realização da fotossíntese bruta, possibilitando uma maior produção de fotoassimilados, implicando positivamente na produção. É oportuno mencionar que o feijãocaupi possui plasticidade fenotípica e alta variabilidade genética, o que o torna adaptado a várias condições de clima e solo (Freire Filho et al., 2005).

Os resultados encontrados no presente estudo concordam com aqueles apresentados por Bezerra et al. (2009), que verificaram redução de $63 \%$ no número de vagem por planta quando aumentou a densidade de plantas de 100 mil para 300 mil plantas ha ${ }^{-1}$. Concordam ainda, com aqueles encontrados por Santos (2013), Cardoso e Ribeiro (2006) e Távora et al. (2001), que verificaram efeito linear decrescente no número de vagens por planta, em função de densidades populacionais. Esses autores associam a redução no número de vagens por planta, possivelmente ao abortamento e diminuição no vingamento de flores, devido à competição intraespecífica com o aumento da densidade de plantas. Segundo Bezerra et al. (2014), o número de vagem por planta é um dos principais componentes de produção do feijão-caupi; e sua diminuição com o adensamento de plantas está diretamente relacionada à redução verificada no número de ramos laterais, com o aumento populacional.

A produtividade de grãos de feijão-caupi diminuiu com o aumento do espaçamento entre plantas (Figura 3). Verificou-se aumento de aproximadamente $117 \%$ na produtividade de grãos quando comparadas as densidades de 66.667 e 200.000 plantas ha $^{-1}$, cujas respectivas 
médias foram de 1091,6 e 2367,6 $\mathrm{kg} \mathrm{ha}^{-1}$. Constata-se, portanto, um aumento significativo no rendimento de grãos, apesar da redução do número de vagem com o adensamento populacional. É importante ressaltar que embora o efeito da densidade de plantas sobre o número de vagens por planta tenha sido negativo (Figura 2), sobre a altura de planta, o efeito foi positivo (Figura 1), o que certamente, contribuiu para aumento do número de ramos laterais, e com o aumento da densidade de plantas, repercutiu positivamente no rendimento de grãos. Também, certamente, as particularidades de cada cultivar e as densidades populacionais, com a máxima densidade de 200.000 plantas ha $^{-1}$, contribuíram para os resultados de rendimento de grãos obtidos no presente estudo. A relação entre o número de vagens por planta e o número de ramos laterais foi reportada por Bezerra et al. (2014).

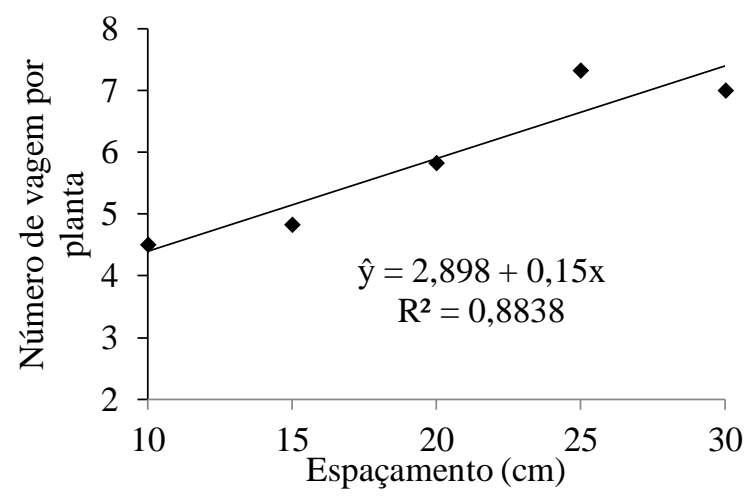

Figura 2 Número de vagens por planta em feijãocaupi, em função de diferentes espaçamentos.

Comportamento semelhante ao encontrado no presente estudo para rendimento de grãos de feijão-caupi, em função $\mathrm{da}$ densidade populacional foi observado por Guimarães et al. (2017) que, estudando sistemas de tutoramento e espaçamentos de plantio na produção de feijão de metro, observaram maior produtividade de grãos com o aumento da densidade de plantas. Santos (2013) observou incremento na produtividade de grãos de feijão-caupi de $13 \%$ ao comparar a densidade de 127 mil plantas com a de 20 mil plantas por hectare. Aumentos no rendimento de grãos em resposta a maior densidade de plantas foram reportados por Njoku e Muoneke (2008) e Naim e Jabereldar (2010).

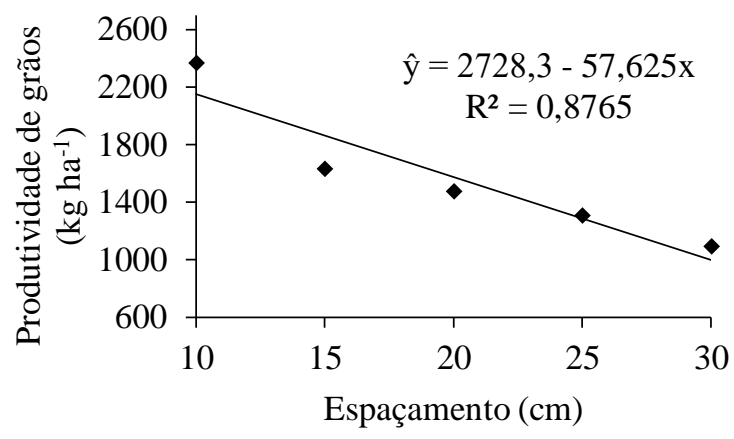

Figura 3 Produtividade de grãos de feijão-caupi em função de diferentes espaçamentos.

Considerando a densidade de 100 mil plantas ha $^{-1}$, a média de rendimento de grãos encontrada no presente estudo $\left(1.477,6 \mathrm{~kg} \mathrm{ha}^{-1}\right)$ superou em $16 \%$, a média encontrada por Bezerra et al. (2014) para feijão-caupi, cv BRS Novaera $\left(1.274,91 \mathrm{~kg} \mathrm{ha}^{-1}\right)$ cultivado em Alvorada do Gurguéia, PI. Esses autores verificaram redução de $60 \%$ no rendimento de grãos quando comparadas às densidades de 100 mil e 500 mil plantas $\mathrm{ha}^{-1}$. O rendimento de grãos encontrado no presente estudo para a densidade de 133.333 plantas ha ${ }^{-1}\left(1635,7 \mathrm{~kg} \mathrm{ha}^{-1}\right)$ foi bem próximo da produtividade máxima encontrada por Oliveira (2015) para feijão-caupi, associada à densidade de 241.000 plantas ha ${ }^{-1}\left(1.668,86 \mathrm{~kg} \mathrm{ha}^{-1}\right) \mathrm{e}$ lâmina de 390,88 mm, em estudo conduzido em Terezina, PI. Bezerra et al. (2008) afirmam que altas densidades de plantio podem afetar a capacidade produtiva das plantas, ocasionando redução na produção de grãos.

A expressão do potencial produtivo do feijãocaupi depende da combinação favorável de um conjunto de fatores, destacando-se dentre eles, a densidade populacional, a qual influência diretamente as características morfológicas, fisiológicas e de rendimento de grãos, bem como, o aproveitamento dos recursos tecnológicos, ambientais e de manejo (Bezerra et al., 2014).

\section{Conclusão}

Recomenda-se a densidade de 200.000 plantas $\mathrm{ha}^{-1}$ para incrementos na produtividade de grãos de feijão-caupi na região Norte da Bahia.

\section{Referências}


Bezerra, A. A. de C.; Alcântara Neto, F. de; Neves, A. C. das; Maggioni, K. Comportamento morfoagronômico de feijãocaupi, cv. BRS Guariba, sob diferentes densidades de plantas. Revista de Ciências Agrárias, v. 55, n. 3, p. 184-189, 2012. http://dx.doi.org/10.4322/rca.2012.059

Bezerra, A. A. de C.; Távora, F. J. A. F.; Freire Filho, F. R.; Ribeiro, V. Q. Morfologia e produção de grãos em linhagens modernas de feijão-caupi submetidas a diferentes densidades populacionais. Revista de Biologia e Ciências da Terra, v. 8, n. 1, p. 85-93, 2008. http://joaootavio.com.br/bioterra/workspace/uploads/artig os/bezerra-518172fab9912.pdf

Bezerra, A. A. de C.; Neves, A. C. das; Neto, F. de A.; Silva Júnior, J. V. da. Morfofisiologia e produção de feijão-caupi, cultivar BRS Novaera, em função da densidade de plantas. Revista Caatinga, v. 27, n. 4, p. 135-141, 2014.

https://periodicos.ufersa.edu.br/index.php/caatinga/article /view/3287

Bezerra, A. A. de C.; Távora, F. J. A. F.; Freire Filho, F. R.; Ribeiro, V. Q. Características de dossel e de rendimento em feijão-caupi ereto em diferentes densidades populacionais. Pesquisa Agropecuária Brasileira, v. 44, n. $10, \quad$ p. 1239-1245, 2009. http://dx.doi.org/10.1590/S0100-204X2009001000005

Bezerra, M. A. F.; Oliveira, F. A. de.; Bezerra, F. T. C.; Pereira, W. E.; Silva, S. A. da. Cultivo de feijão-caupi em Latossolos sob o efeito residual da adubação fosfatada. Revista Caatinga, v. 27, n. 1, p. 109-115, 2014. https://periodicos.ufersa.edu.br/index.php/caatinga/article /view/2816/pdf_92

Brito, L. C. R. de. Comportamento de cultivares de feijão-caupi de porte semiprostrado em resposta à diferentes densidades de plantas. 2014. 90 p. Dissertação (Mestrado em Agronomia) Universidade Federal do Piauí, Teresina, 2014. http://ufpi.br/arquivos_download/arquivos/ppga/files/Diss erta\%C3\%A7\%C3\%A30\%20Luc\%C3\%A9lia.pdf

Camara, F. T.; Mota, A. M. D.; Nicolau, F. E. A.; Pinto, A. A.; Silva, J. M. F. Produtividade de feijão caupi crioulo em função do espaçamento entre linhas e número de plantas por cova. Revista de Agricultura Neotropical, v. 5, n. 2, p. 19-24. 2018. https://periodicosonline.uems.br/index.php/agrineo/article /view/2282/2140
Cardoso, M. J.; Melo, F. de B. Plantio. In: BastoS, E. A. (Ed.). Cultivo de Feijão-Caupi. 2. ed. Brasília, DF: Embrapa, 2017. Versão eletrônica. (Embrapa Meio-Norte. Sistema de produção, 2; Embrapa Amazônia Ocidental. Sistema de produção, 2; Embrapa Agrobiologia. Sistema de produção, 4). https://ainfo.cnptia.embrapa.br/digital/bitstream/item/161 208/1/SistemaProducaoCaupiCapituloPlantio.pdf

Cardoso, M. J.; Ribeiro, V.Q. Desempenho agronômico do feijão-caupi, cv. Rouxinol, em função de espaçamento entre linhas e densidade de plantas sob regime de sequeiro. Revista Ciência Agronômica, v. 37, p. 102105 , 2006. http://ccarevista.ufc.br/seer/index.php/ccarevista/article/vi ew/223/218

EMBRAPA ARROZ E FEIJÃO. Dados conjunturais da produção de feijão comum (Phaseolus vulgaris L.) e caupi (Vigna unguiculata (L.) Walp) no Brasil (1985 a 2017): área, produção e rendimento. Santo Antônio de Goiás: Embrapa Arroz e Feijão, 2018.

http://www.cnpaf.embrapa.br/socioeconomia/index.htm

FAO (2018). FAOSTAT. Crops. Cow peas, dry. http://faostat3.fao.org/browse/Q/QC/E

Freire Filho, F. R. Feijão-caupi no Brasil: produção, melhoramento genético, avanços e desafios. Embrapa Meio Norte, Teresina, 84 p. 2011. https://www.alice.cnptia.embrapa.br/bitstream/doc/91683 1/1/feijaocaupi.pdf

Freire Filho, F. R.; Lima, J. A. De A.; Ribeiro, V. Q. (Ed.). Feijão-caupi: avanços tecnológicos. Brasília: Embrapa Informação Tecnológica, 2005. 519p.

Guimarães, M. A; Lemos Neto, H. S.; Araújo, R. B.; Lima Neto, B. P.; Silva, V. B.; Mesquita, R. O. Sistemas de tutoramento e espaçamentos de plantio na produção de feijão de metro. Horticultura Brasileira, v. 35 , n. 4, p. 613620, 2017. http://dx.doi.org/10.1590/S0102053620170422

Locatelli, V.; Medeiros, R. D. de; Smiderle, O.; Albuquerque, J. Produtividade de vagens verdes de Feijão-caupi sob lâminas de irrigação em plantio direto no cerrado Roraimense. In: Congresso Nacional De Feijão-Caupi, 3., Recife, 2013. https://www.alice.cnptia.embrapa.br/bitstream/doc/96178 1/1/370d.pdf 
Naim, A. M.; Jabereldar, A. A. Effect of Plant density and Cultivar on Growth and Yield of Cowpea (Vigna unguiculata L.Walp). Australian Journal of Basic and Applied Sciences, v. 4, n. 8, p. 3148-3153, 2010. http://www.ajbasweb.com/old/ajbas/2010/3148-3153.pdf

Njoku, D. N.; Muoneke, C. O. Effect of cowpea planting density on growth, yield and productivity of component crops in cowpea/cassava intercropping system. Journal of Tropical Agriculture, Food, Environment and Extension, v. 7, n. 2, p. 106-113, 2008. http://dx.doi.org/10.4314/as.v7i2.1591

Oliveira, S. R. M. de; Andrade Júnior, A. S. de.; Ribeiro, V. Q.; Brito, R. R. de.; Carvalho, M. $\mathrm{W}$. Interação de níveis de água e densidade de plantas no crescimento e produtividade do feijão-caupi, em Teresina - PI. Irriga, v. 20, n. 3, p. 502-513, 2015. https://doi.org/10.15809/irriga.2015v20n3p502

Oliveira, O. M. S. de. Capacidade competitiva de cultivares de feijão-caupi (Vigna unguiculata (L.) Walp) combinada com espaçamento na supressão de plantas daninhas. 2014. 70p. Tese (Doutorado em Agronomia Tropical) - Universidade Federal do Amazonas, Manaus, 2014. https://tede.ufam.edu.br/handle/tede/4360

Oliveira, S. R. M. de. Densidade populacional do feijão-caupi sob níveis de irrigação. 2013. 104p. Tese (Doutorado em Engenharia Agrícola) - Universidade Federal do Ceará, Fortaleza, 2013. http://www.repositorio.ufc.br/handle/riufc/10584

Rocha, M. de M.; Silva, K. J. D.; Menezes Junior, J. A. de. Importância econômica. In: BASTOS, E. A. (Ed.). Cultivo de FeijãoCaupi. 2. ed. Brasília: Embrapa, 2017. https://ainfo.cnptia.embrapa.br/digital/bitstream/item/161 169/1/SistemaProducaoCaupiCapituloImportanciaEcono mica.pdf

Santos, C. A. F. BRS Tapaihum, BRS Carijó e BRS Acauã: novas cultivares de feijão-caupi para o vale do São Francisco. In: Congresso Brasileiro De Olericultura, 51. Anais... Viçosa: ABH. 3086-3094. 2011. https://www.alice.cnptia.embrapa.br/alice/handle/doc/897 481

Santos, J. F. dos. Resposta do feijão-caupi a diferentes densidades de plantas em Neossolo Regolítico no Agreste Paraibano. Revista Tecnologia \& Ciência Agropecuária, v.7, n.4, p. 37-41, 2013. http://revistatca.pb.gov.br/edicoes/volume-07-

2013/volume-7-numero-4-dezembro-2013/tca7407.pdf

Silva, W. C.; Moura, J. G. de; Brito, L. L. M. de; Nicolau, F. E. de A.; Camara, F. T. da. Produtividade de feijão-caupi submetido a diferentes manejos do solo e níveis de adubação mineral. Enciclopédia Biosfera, v. 10, n. 18, p. 2459-2467, 2014. http://www.conhecer.org.br/enciclop/2014a/AGRARIAS/ Produtividade\%20de\%20feijao.pdf

Silva Júnior, E. B.; Fernandes Júnior, P. I.; Oliveira, P. J.; Rumjanek, N. G.; Boddey, R. M.; Xavier, G. R. Eficiência agronômica de nova formulação de inoculante rizobiano para feijão-caupi. Pesquisa Agropecuária Brasileira, v. 47, n. 1, p. 138-141, 2012. https://ainfo.cnptia.embrapa.br/digital/bitstream/ite m/57216/1/Silva-Junior-et-al.-PAB.pdf

Sousa, R. R. de. Densidade populacional e inoculação na cultivar de feijão-caupi BRS Imponete. 2017. 67 p. Dissertação (Mestrado em Agronomia) - Universidade Federal do Piauí, Teresina, 2017. http://repositorio.ufpi.br/xmlui/bitstream/handle/1234567 89/895/DISSERTA\%C3\%87\%C3\%83O-

VERS\%C3\%83O-FINAL.pdf?sequence=1

Taiz, L; Zeiger, E. Fisiologia Vegetal. 5. ed. Porto Alegre: Artmed. 2013. 954p.

Távora, F. J. A. F.; Nogueira, S. L.; Pinho, J. L. N. de. Arranjo e população de plantas em cultivares de feijão-de-corda com diferentes características de copa. Ciência Agronômica, v.32, p. 69-77, 2001. www.ccarevista.ufc.br/site/down.php?arq=08rca32.pdf 